\title{
hydra
}

\section{POLITICAS DA FÉ E POLÍTICAS DO CETICISMO NO PENSAMENTO DO HISTORIADOR MICHAEL OAKESHOIT}

Marlon Andrey Nunes da Silva'

OAKESHOTT, Michael. A política da fé e a política do ceticismo. Tradução de Daniel Lena Marchiori Neto. 1 ed. - São Paulo: É Realizações, 2018. 232p.

Em meio ao turbulento cenário político que o Brasil tem vivido nos últimos anos, com a polarização do debate entre grupos de "direita" e de "esquerda", é visível em muitos lugares o empobrecimento do repertório político e a baixa qualidade das discussões. Nesse sentido, a obra póstuma do historiador britânico Michael Oakeshott (1901-1990), produzida na década de $1950^{2}$ e publicada pela primeira vez em 1996 pela editora Yale University Press, intitulada The Politics of Faith and The Politics of Scepticism, e publicada no Brasil, no ano de 2018 pela editora É Realizações, vem em boa hora para auxiliar na reflexão de acadêmicos e pesquisadores que discutem temas políticos e sociais.

Sobre Michael Oakeshott, ele nasceu no ano de 1901 na Inglaterra e estudou História na Universidade de Cambridge. Tendo sido professor por um curto período de tempo na Universidade de Oxford, Oakeshott se tornou professor catedrático de Ciência Política na London School of Economics e foi o responsável pela criação do curso de mestrado em História do Pensamento Político na instituição. Como pensador e escritor, podemos localizar as ideias e as obras do autor na chamada "tradição conservadora britânica", que tem como principal herança ideias e conceitos provenientes da tradição filosófica "cética" e "empírica".

\footnotetext{
'Mestre e licenciado em História pela Universidade Estadual de Montes Claros (Unimontes/MG). Especialista em Educação Moderna pela Pontifícia Universidade Católica do Rio Grande do Sul (PUCRS). Contato: marlonandrey@hotmail.com (http://lattes.cnpq.br/4020656592317808).

2MARCHIORI NETO, Daniel Lena. Michael Oakeshott: a política da fé e a política do ceticismo. Jornal Estadão. Disponível em: https://estadodaarte.estadao.com.br/michael-oakeshott-apolitica-da-fe-e-a-politica-do-ceticismo/. Acesso em 6 de julho de 2020.
} 


\section{hydra}

A obra do historiador, traduzida no Brasil como A política da fé e a política do ceticismo (2018), intentou discutir duas maneiras de se enxergar a política que foi ganhando forma no mundo Ocidental, a saber, as políticas da fé, que tendem a ter uma visão mais otimista do ser humano e de sua capacidade de transformar o mundo, e as políticas do ceticismo, que tendem a ser mais pessimistas. Logo no início da obra, em seu prefácio, o polêmico filósofo e professor da PUC-SP, Luiz Felipe Pondé, apresenta o autor ao público brasileiro, deixando explicita a importância que Michael Oakeshott tem na tentativa de esclarecer o conceito de "conservadorismo político", que, segundo Pondé, é mal compreendido no âmbito do senso comum e até da academia. $^{3}$

A obra também conta com uma introdução do professor e pesquisador norte-americano Timothy Fuller, que foi um dos responsáveis pela organização dos textos e livros de Oakeshott logo após a sua morte, em 1990. Na introdução, o professor Fuller identificou as políticas da fé que surgiram na modernidade com a "antropologia pelagiana", ao passo que as políticas do ceticismo se aproximariam de uma "visão agostiniana"4 do ser humano. $5 \mathrm{Em}$ outro momento, o autor afirma que o ceticismo político de Oakeshott nos chama a atenção para a necessidade da mudança "sem o estímulo de expectativas ilusórias", expectativas estas que seriam uma das "marcas" das políticas da fé. 6 No final da obra, há um posfácio do tradutor do livro, o professor Daniel Lena Marchiori Neto, que apresenta uma breve biografia do

\footnotetext{
3 OAKESHOTT, Michael. A política da fé e a política do ceticismo. Tradução de Daniel Lena Marchiori Neto. 1 ed. São Paulo: É Realizações, 2018. p. 7-10.

${ }^{4}$ O termo "pelagianismo" na literatura teológica indica uma posição religiosa (no contexto do cristianismo) que tende a minimizar os efeitos da Queda, afirmando que o ser humano é bom e capaz de conquistar a salvação por méritos próprios. Essa posição, que é atribuída ao teólogo Pelágio (350-423), teve a forte oposição de Santo Agostinho (354-430), que defendia que o ser humano é pecador por natureza e carente da graça de Deus. In: SILVA, Dayvid da. O pecado original: raízes histórico-teológicas de uma controvérsia. Revista Cultura Teológica - v. 17 - n. 66 - JAN/MAR, 2009. p. 73-91.

5 OAKESHOTT, Michael. A política da fé e a política do ceticismo. Tradução de Daniel Lena Marchiori Neto. 1 ed. São Paulo: É Realizações, 2018. p. 15.

6 OAKESHOTT, Michael. A política da fé e a política do ceticismo. Tradução de Daniel Lena Marchiori Neto. 1 ed. São Paulo: É Realizações, 2018. p. 22.
} 


\section{$\underline{\text { hydra }}$}

autor, suas principais obras e ideias, e finaliza tecendo comentários ao livro A Política da Fé e a Política do Ceticismo.7

A obra contém seis capítulos, sendo o primeiro uma apresentação de Michael Oakeshott ao tema e o sexto uma discussão sobre suas conclusões. No caso do primeiro capítulo, intitulado Introdução, o historiador afirma que o "vício" da política contemporânea reside no fato de a mesma "lançar uma excessiva visão sobre o futuro e um escasso olhar sobre o passado". 8 Nesse sentido, o autor direciona o leitor a hipótese central de seu livro, que consiste no entendimento de que a política contemporânea do Ocidente pode ser dividida em dois polos, que ele conceituou como "políticas da fé" e "políticas do ceticismo". ${ }^{9}$ Ainda em seu capítulo introdutório, Oakeshott apresenta uma posição cética no que tange a teorias e propostas governamentais que busquem resolver as "ambiguidades" da vida social e política, pois, para o autor, isto acabaria levando a sociedade aos extremos e a intensa polarização. ${ }^{10}$

No segundo capítulo, intitulado A identificação da ambiguidade, o autor, em um primeiro momento, buscou apresentar uma definição ampla sobre a "política da fé". Para Michael Oakeshott, na política da fé "a atividade de governar está a serviço da perfeição da humanidade". Segundo ele, essa visão é caracterizada por um certo "otimismo cósmico", por uma crença na bondade e perfeição humana, por uma disposição em acreditar que o governo teria a capacidade de melhorar o mundo e de aprimorar os seres humanos, seja através da educação, da ciência ou de políticas públicas. Para o historiador, essa forma de entender a política pode ser caracterizada por "realizar abstrações" sobre a sociedade ideal, criando

\footnotetext{
7 OAKESHOTT, Michael. A política da fé e a política do ceticismo. Tradução de Daniel Lena Marchiori Neto. 1 ed. São Paulo: É Realizações, 2018. p. 199-225.

8 OAKESHOTT, Michael. A política da fé e a política do ceticismo. Tradução de Daniel Lena Marchiori Neto. 1 ed. São Paulo: É Realizações, 2018. p. 30.

9 OAKESHOTT, Michael. A política da fé e a política do ceticismo. Tradução de Daniel Lena Marchiori Neto. 1 ed. São Paulo: É Realizações, 2018. p. 51-52.

10 OAKESHOTT, Michael. A política da fé e a política do ceticismo. Tradução de Daniel Lena Marchiori Neto. 1 ed. São Paulo: É Realizações, 2018. p. 53.
} 


\section{$\underline{\text { hydra }}$}

"teorias sociais" e identificando na sociedade os seus problemas e propondo soluções, e, desta maneira, políticos e partidos que acolhem essa forma de ver a política acabam criando "Estados grandes", acumulando poder, ampliando os mecanismos jurídico-institucionais com o intuito de "aprimorar a sociedade". ${ }^{11}$

Em um segundo momento, Oakeshott apresenta a visão que ele denominou de "política do ceticismo". Para o autor, os céticos em política podem ser definidos como aqueles que suspeitam da bondade humana e são descrentes quanto à capacidade intelectual de se conhecer lem sua totalidade) as dinâmicas sociais e políticas e de propor soluções para elas. Nesse sentido, o autor afirma que o cético tende a suspeitar de teorias e abstrações sobre a vida humana e a sociedade, pautando sua atividade de governar não "em uma doutrina sobre a natureza humana, mas em uma leitura da conduta humana". O cético, na visão do historiador, é aquele que defende que "o governo não deve ser o arquiteto de um modo perfeito de vida", ou "de uma maneira aprimorada de vida", ou mesmo "de qualquer forma de vida". Portanto, "a atividade de governar subsistiria não porque é boa, mas porque é necessária". Oakeshott também afirma que nesta visão, o primeiro objetivo do governo é manter a ordem, e o segundo, seria buscar melhorias, entretanto, essas melhorias não devem estar fundamentadas em "teorias sociais" ou "racionalismos políticos", mas sim, a partir de questões específicas, problemas específicos, com intervenções "pontuais" e "cirúrgicas". 12

No terceiro capítulo, As contingências da fé, Michael Oakeshott se debruça sobre o pensamento das políticas da fé, afirmando que os adeptos dessa visão buscam constantemente a concentração de poder, sendo este aumento de poder um requisito necessário na tentativa de "melhorar o

11 OAKESHOTT, Michael. A política da fé e a política do ceticismo. Tradução de Daniel Lena Marchiori Neto. 1 ed. São Paulo: É Realizações, 2018. p. 57-67.

12OAKESHOTT, Michael. A política da fé e a política do ceticismo. Tradução de Daniel Lena Marchiori Neto. 1 ed. São Paulo: É Realizações, 2018. p. 67-77. 


\section{$\underline{\text { hydra }}$}

mundo". Em outro momento, o historiador apresenta o principal arquiteto dessas políticas da fé, que segundo o autor, seria o filósofo e cientista britânico Francis Bacon (1561-1626). ${ }^{13}$ Para ele, ao analisar as obras e os escritos de Bacon, é possível identificar no cientista o "primeiro princípio" da política da fé que consistiria na visão de que a "atividade humana deveria ser a busca da perfeição". Para o autor, Bacon incentiva uma "restauração daquilo que os homens perderam com a Queda", e nesse sentido, "quando toda a potência dos esforços humanos é metodicamente organizada para se opor à Queda, a imperfeição da condição humana irá, na maior parte, desaparecer". ${ }^{14}$ É nesse sentido que Oakeshott associa o pensamento de Bacon e de todos os adeptos das política das fé a uma espécie de "pelagianismo político", que pode ser definido como a crença de que o ser humano é inerentemente bom e capaz de se aprimorar constantemente.

Em outro momento do seu livro, o autor afirma que a políticas da fé criaram um vocabulário específico, e nesse sentido, novas palavras e frases surgiram, tais como "engenharia social" e "planejamento para a abundância". 15 No final do terceiro capítulo, o historiador apresenta três importantes conclusões a respeito das políticas da fé. A primeira conclusão seria a de que as políticas da fé não surgiram com o lluminismo no século XVIII, mas possuem um parentesco mais distante, podendo ser rastreado até o período final da ldade Média. A segunda conclusão são a de que as políticas da fé não podem ser identificadas com movimentos ou partidos políticos específicos, pois "houve representantes desse estilo de política em todos os campos, em todos os partidos, em todos os movimentos e entre todos os defensores de todas as causas". Apesar de que o autor afirma que o socialismo e o comunismo seriam os principais representantes dessa visão,

\footnotetext{
13 OAKESHOTT, Michael. A política da fé e a política do ceticismo. Tradução de Daniel Lena Marchiori Neto. 1 ed. São Paulo: É Realizações, 2018. p. 96.

14 OAKESHOTT, Michael. A política da fé e a política do ceticismo. Tradução de Daniel Lena Marchiori Neto. 1 ed. São Paulo: É Realizações, 2018. p.97-98.

15 OAKESHOTT, Michael. A política da fé e a política do ceticismo. Tradução de Daniel Lena Marchiori Neto. 1 ed. São Paulo: É Realizações, 2018. p.112.
} 


\section{hydra}

muitos governos classificados como "conservadores" e "liberais" também possuem características semelhantes. A terceira e última conclusão, são a de que as políticas da fé, apesar de sua grande popularidade e influência nas últimas décadas no Ocidente (Oakeshott possivelmente está falando da primeira metade do século $X X$, já que o seu livro foi escrito na década de 1950), não são as únicas formas de se compreender a política, existindo outras visões tão importantes quanto. ${ }^{16}$

Já no quarto capítulo, traduzido como As Contingências do Ceticismo, o autor irá tratar de outra importante forma de se entender a política no mundo moderno e que pode ser apontada como "principal rival" às políticas da fé. Nesse sentido, o historiador apresenta as principais influências intelectuais do ceticismo político, como George Herbert (1593-1633), Thomas Hobbes (1588), Baruch Espinoza (1632-1677), Blaise Pascal (1623-1662), Michel de Montaigne (1533-1592) e David Hume (1711-1776).17 Depois de apresentar as principais influenciais, Oakeshott busca responder o que caracterizaria um político cético. Para o autor, o político cético é aquele que não enxerga a terra "como um mundo a ser explorado", mas como um "palco para atuação", nesse sentido, o cético tem dúvidas "em relação aos resultados dos projetos humanos", em especial, quando esses projetos são realizados em grande escala. Em determinado ponto de sua obra, Michael Oakeshott contextualiza Michel de Montaigne, que foi contemporâneo de Francis Bacon, afirmando que Montaigne não possuía ilusões acerca do poder humano e afirmava a importância dos "costumes" em detrimento dos "projetos de engenharia social", pois "o costume é soberano na vida humana; é uma segunda Natureza, não menos poderosa". 18

\footnotetext{
16 OAKESHOTT, Michael. A política da fé e a política do ceticismo. Tradução de Daniel Lena Marchiori Neto. 1 ed. São Paulo: É Realizações, 2018. p. 113-115.

17 OAKESHOTT, Michael. A política da fé e a política do ceticismo. Tradução de Daniel Lena Marchiori Neto. 1 ed. São Paulo: É Realizações, 2018. p. 126.

18 OAKESHOTT, Michael. A política da fé e a política do ceticismo. Tradução de Daniel Lena Marchiori Neto. 1 ed. São Paulo: É Realizações, 2018. p. 127.
} 


\section{$\underline{\text { hydra }}$}

Em outro momento, Oakeshott afirma que das três grandes revoluções do mundo moderno, a Revolução Americana (1775-1783), a Revolução Francesa (1789-1799) e a Revolução Russa (1917-1923), duas foram influenciadas pelo ceticismo político, no caso, a Revolução Americana e a Francesa, apesar de que a última, afirmou o autor, acabou sendo "desviada para o caminho da fé". 19 Outra questão que merece destaque são duas afirmações que o historiador fez a respeito do ceticismo político. O primeiro é a ideia de que os céticos rejeitam o "pelagianismo" político que ele considera a base das políticas da fé, a crença na capacidade humana de resolver totalmente ou quase totalmente os seus problemas individuais e sociais. $O$ segundo é a separação que os céticos fizeram entre religião e política. ${ }^{20}$ No caso do último, a ideia central não é a de que a religião deva ser rejeitada e considerada inferior, mas sim, o afastamento das pretensões religiosas do mundo da política (incluindo as formas "messiânicas de política" e as "escatologias secularizadas"), que é visto na visão do autor, como um campo prático e pragmático, que deve se manter longe de especulações metafísicas e racionalistas.

No quinto capítulo, denominado de A Nêmesis da Fé e do Ceticismo, o autor buscou trabalhar os pontos fracos e os perigos de cada uma das visões que foram apresentadas. Em geral, Oakeshott apresentou os riscos que poderiam advir para a sociedade caso a atividade política se tornasse imobilizada por alguma dessas duas formas de se entender as dinâmicas do poder e da vida social. ${ }^{21}$ Segundo ele, a nêmesis das políticas da fé seria o "excesso", a tentativa incansável de ampliação do poder e do tamanho do Estado com o intuito de promover as mudanças necessárias para uma

19 OAKESHOTT, Michael. A política da fé e a política do ceticismo. Tradução de Daniel Lena Marchiori Neto. 1 ed. São Paulo: É Realizações, 2018. p. 132.

20 OAKESHOTT, Michael. A política da fé e a política do ceticismo. Tradução de Daniel Lena Marchiori Neto. 1 ed. São Paulo: É Realizações, 2018. p. 133.

21 OAKESHOTT, Michael. A política da fé e a política do ceticismo. Tradução de Daniel Lena Marchiori Neto. 1 ed. São Paulo: É Realizações, 2018. p. 146. 


\section{$\underline{\text { hydra }}$}

sociedade "perfeita" ou quase perfeita. ${ }^{22}$ O historiador enxerga nesse excesso - embrião de diversos problemas sociais, principalmente de natureza econômica. Do outro lado, Oakeshott também chama a atenção para a nêmesis do ceticismo, que segundo o autor seria o "excesso de moderação", levando a sociedade a uma eventual estagnação. ${ }^{23}$ Para ele, essa estagnação é ruim, pois a sociedade está em constante mudança e carece de governos e líderes que continuamente promovam transformações no aspecto político, jurídico e institucional.

No final do quinto capítulo, Michael Oakeshott faz uma afirmação importante, a de que tanto as políticas da fé quanto as políticas do ceticismo são de grande importância para o bom andamento da sociedade. Segundo ele, dizer que "cada estilo de governo, quando opera sozinho, é autodestrutivo", é chamar a atenção para o fato de que o "que pode salválo é algo que o outro estilo é capaz de fornecer", em outras palavras, as políticas da fé e do ceticismo "não são meramente oponentes, mas também parceiros". Entretanto, na página final do capítulo, o autor deixa claro que o pensamento cético é o que está mais perto dessa moderação e que os adeptos das políticas da fé tendem a se distanciar mais desse equilíbrio. ${ }^{24}$

Em sua Conclusão, o autor retoma as ideias principais que ele buscou trabalhar no livro, afirmando que a vida social e política são complexas e ambíguas, e que nesse sentido, é perigosa qualquer tentativa de eliminação da ambiguidade. ${ }^{25} \mathrm{O}$ historiador também faz referências a importantes nomes da tradição cética ${ }^{26}$, faz críticas a algumas ideias e posturas de adeptos das

\footnotetext{
22 OAKESHOTT, Michael. A política da fé e a política do ceticismo. Tradução de Daniel Lena Marchiori Neto. 1 ed. São Paulo: É Realizações, 2018. p. 164-169.

23 OAKESHOTT, Michael. A política da fé e a política do ceticismo. Tradução de Daniel Lena Marchiori Neto. 1 ed. São Paulo: É Realizações, 2018. p. 169.

24 OAKESHOTT, Michael. A política da fé e a política do ceticismo. Tradução de Daniel Lena Marchiori Neto. 1 ed. São Paulo: É Realizações, 2018. p. 173-176.

25 OAKESHOTT, Michael. A política da fé e a política do ceticismo. Tradução de Daniel Lena Marchiori Neto. 1 ed. São Paulo: É Realizações, 2018. p. 180-181.

26 OAKESHOTT, Michael. A política da fé e a política do ceticismo. Tradução de Daniel Lena Marchiori Neto. 1 ed. São Paulo: É Realizações, 2018. p. 193.
} 


\section{hydra}

políticas da fé ${ }^{27}$ e finaliza seu livro chamando a atenção para o fato de que, se quisermos ter um debate frutífero e democrático, faz-se necessário ampliarmos o nosso vocabulário e os nossos conceitos acerca de questões políticas e sociais. ${ }^{28}$

A partir dessa última afirmação de Michael Oakeshott, entendemos que a leitura de sua obra é um convite para ampliarmos nosso vocabulário e repertório político, além de introduzir novos conceitos e novas discussões em torno de questões sociais, políticas e econômicas, ampliando o repertório conceitual de historiadores e pesquisadores de temas políticos em geral. A despeito de concordarmos ou não com as visões e posições políticas do historiador britânico, as ideias de sua obra nos instigam a promovermos um debate mais amplo e moderado.

\section{REFERÊNCIAS}

MARCHIORI NETO, Daniel Lena. Michael Oakeshott: a política da fé e a política do ceticismo. Jornal Estadão. Disponível em: https://estadodaarte.estadao.com.br/michael-oakeshott-a-politica-da-fe-e-apolitica-do-ceticismo/. Acesso em 6 de julho de 2020.

OAKESHOTT, Michael. A política da fé e a política do ceticismo. Tradução de Daniel Lena Marchiori Neto. 1 ed. São Paulo: É Realizações, 2018.

SILVA, Dayvid da. O pecado original: raízes histórico-teológicas de uma controvérsia. Revista Cultura Teológica - v. 17 - n. 66 - JAN/MAR, 2009.

Resenha recebida em 17/07/2020 e aprovada em 12/02/2021.

27 OAKESHOTT, Michael. A política da fé e a política do ceticismo. Tradução de Daniel Lena Marchiori Neto. 1 ed. São Paulo: É Realizações, 2018. p. 182, 195.

28 OAKESHOTT, Michael. A política da fé e a política do ceticismo. Tradução de Daniel Lena Marchiori Neto. 1 ed. São Paulo: É Realizações, 2018. p. 198. 